\title{
A STUDY ON THE ABRASIVE RESISTANCE OF Ni BASED LASER COATINGS WITH WC HARD PHASE
}

\author{
prof. Ing. Zita IŽDINSKÁ, CSc. ${ }^{1}$, Ing. Alena BRUSILOVÁ,PhD. ${ }^{1}$, Ing. Karol IŽDINSKÝ, \\ $\mathrm{CSc}^{2}$ \\ ${ }^{1}$-Institute of Technologies and Materials, Faculty of Mechanical Engineering, Slovak University \\ of Technology in Bratislava, Pionierska 15, 83102 Bratislava, Slovak Republic, \\ zita.izdinska@stuba.sk \\ ${ }^{2}$ Institute of Materials and Machine Mechanics of Slovak Academy of Sciences, Račianska 75, \\ 83102 Bratislava, Slovak Republic
}

\begin{abstract}
Wear properties of composite laser cladding on the basis of $\mathrm{Ni}$ with a $50 \%$ presence of $W C$ particles on the dependence of laser beam power output and speed of cladding were investigated in this paper. Properties are compared with reference Ni based laser claddings without WC particles. Laser beam power output of 4.3 and $3.7 \mathrm{~kW}$ and cladding speed of 3, 5 and $7 \mathrm{~mm} / \mathrm{s}$ were used for the preparation of test pieces. All types of prepared claddings were compact without visible internal defects. With increased cladding speed, the hardness of Ni matrix decreased. Wear resistance of Ni based laser claddings with WC particles were dependent on the speed of laser cladding. The presence of WC particles increased the wear resistance of Ni based laser claddings 5 fold.
\end{abstract}

KEYWORDS: NiCrBSi powder, WC particles, laser cladding; wear resistance, pin on disc test

\section{INTRODUCTION}

The wear resistance of NiCrBSi coatings, especially abrasive wear, can be significantly increased by adding refractory carbides, such as $\mathrm{WC}, \mathrm{NiC}, \mathrm{VC}, \mathrm{NbC}$ and $\mathrm{TaC}$, into the NiCrBSi matrix [1-2]. The basic structure then contains a relatively soft matrix and a harder phase that provides high abrasion resistance[3-4].

Metal matrix composites are built up by blowing metal powder simultaneously with hard powder, usually carbides, into a melt pool that a laser beam generates. The aim is to keep the carbides intact with minimal dissolution, and melt only the matrix material. Because of the low heat input of laser cladding this can usually be achieved, providing that the difference of matrix and carbides melting temperatures are high enough.

Within this article, a comparison among the abrasive wear behavior of composite NiCrBSi coatings reinforced with WC particles prepared by various laser beam parameters is made with the aim of establishing relations between the tribological response of the material and the structure that results from different deposition conditions.

\section{EXPERIMENT}

Within this study a NiCrBSi based powder reinforced composite with WC particles was used. The matrix composition of NP 60 powder, produced by the Welding Research Institute in Bratislava is given in Table 1. This powder is mixed with WC particles and used as feedstock material for laser clad coating (Tab. 2). 


\begin{tabular}{|c|c|c|c|c|c|c|}
\hline Content (wt.\%) & Ni & C & Si & B & Fe & Cr \\
\hline NP 60 & Bal & 0,6 & 5 & 3,9 & 5 & 16 \\
\hline
\end{tabular}

Tab. 1 - Chemical composition of NiCrBSi powder

\begin{tabular}{|l|c|c|}
\hline Powders & NP 60 & WC \\
\hline Content (wt. \%) & 50 & 50 \\
\hline
\end{tabular}

Tab. 2 - Composition of composite powder blend

In laser surface cladding, the laser beam intercepts the feedstock powder and the surface at the same time, thus causing both to melt and the powder to become deposited on the base material. The powder is introduced into the beam by means of a suitable feed device. The laser used in this study was a $\mathrm{CO}_{2}$ Ferranti Photonick AF8 Fust Axial Flow laser operating at 3.5 and 4.3 $\mathrm{kW}$ power output. The composite powder was injected into the nozzle by means of an argon gas stream with a rate of $91 / \mathrm{min}$, transported from the dosing unit. Another stream of the same gas was emitted through the nozzle at a rate of $15 \mathrm{l} / \mathrm{min}$ in order to avoid surface oxidation and to preserve the laser optics.

The powder was cladded on $120 \times 100 \times 10 \mathrm{~mm}$ mild steel plates $(0.17 \% \mathrm{C}, 0.007 \% \mathrm{~N}$, $0.045 \% \mathrm{P}, 0.045 \% \mathrm{~S}$ ) in the form of successive weld passes. Laser claddings prepared this way were used for further investigations. As-cladded samples differ from each other in laser beam parameters namely in the power of the laser beam and the beam scanning speed. Laser beam cladding parameters and specimen designations are given in Tab. 3.

\begin{tabular}{|c|c|c||c|c|c|}
\hline $\begin{array}{c}\text { Specimen } \\
\text { designation }\end{array}$ & $\begin{array}{c}\text { Laser beam } \\
\text { power }\end{array}$ & Cladding speed & $\begin{array}{c}\text { Specimen } \\
\text { designation }\end{array}$ & $\begin{array}{c}\text { Laser beam } \\
\text { power }\end{array}$ & Cladding speed \\
\hline $3,7 / 3$ & & $3 \mathrm{~mm} / \mathrm{s}$ & $4,3 / 3$ & & $3 \mathrm{~mm} / \mathrm{s}$ \\
$3,7 / 5$ & $3,7 \mathrm{~kW}$ & $5 \mathrm{~mm} / \mathrm{s}$ & $4,3 / 5$ & $4,3 \mathrm{~kW}$ & $5 \mathrm{~mm} / \mathrm{s}$ \\
$3,7 / 7$ & $7 \mathrm{~mm} / \mathrm{s}$ & $4,3 / 7$ & & $7 \mathrm{~mm} / \mathrm{s}$ \\
\hline
\end{tabular}

Tab. 3 - Laser beam cladding parameters

The effect of laser cladding parameters on the coating structure was studied on asreceived specimens. Standard metallographic procedures, based on light microscopy methods were used. Coatings were observed in the longitudinal and transverse sections with particular attention paid to the bonding at the coating substrate interface.

Microstructural studies were conducted using scanned electron microscopy (SEM) observed through the electron microscope JEOL - JSM-7600F. Vickers microhardness measurements were performed on Future Tech fully automated microhardness tester FM-ARS 9000 with a $100 \mathrm{~g}$ load providing the vertical hardness profile of the metal matrix from the surface to the substrate.

Tribological properties were evaluated by pin-on-disc wear test in vertical configuration on rollers with a diameter of $9 \mathrm{~mm}$ cut out from the coated plate. All tests were carried out by a pin load of $6.125 \mathrm{~N}$ on a track of $146.10^{3}$ and $438.10^{3} \mathrm{~mm}$. Abrasive paper with $\mathrm{SiC}$ grains and granularity of 220 micrometers was used as an abrasent. The wear was evaluated by measuring of the weight loss of the material. The principle of the test is schematically presented in Fig. 1. 


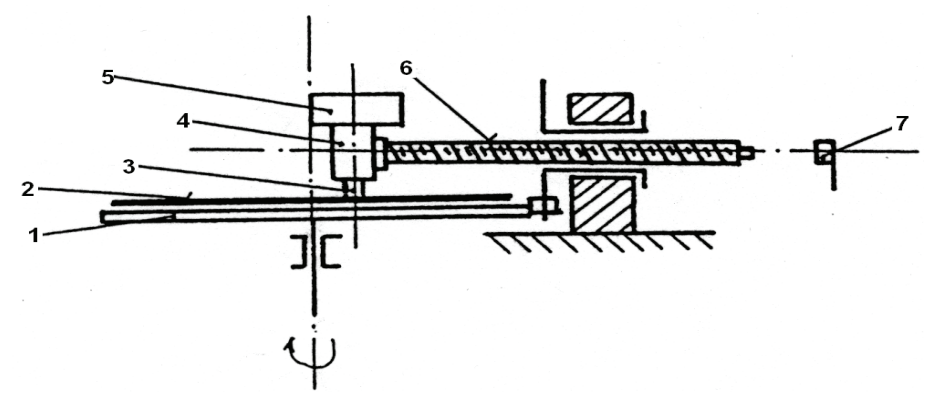

Fig.1 - Schematic view on the pin-on-disc testing machine

1 - board, 2 - abrasive paper, 3 -specimen, 4-clamping head, 5-load, 6-adjusting, 7 -power switch

\section{RESULTS AND DISCUSSION}

Fig. 2 shows the cross-sectional morphology of the laser-clad coating with $50 \%$ WC particles manufactured by a $3.7 \mathrm{~kW}$ laser. The bright phases of the coating consist mainly of WC, their distribution in the coating is not homogenous. WC particles sank towards the bottom of the coating, which is consistent with other reports [5]. The reason why WC particles tend to sink to the bottom of the melt pool is due to the great difference in powder density between WC and Ni based alloy. The lower melting points and slower solidification rates of Ni based alloys allow time for the WC particles to sink towards the bottom of the melt pool.

Visual inspection of all coating types revealed a good continuous appearance of received passes without any signs of lack of adhesion.

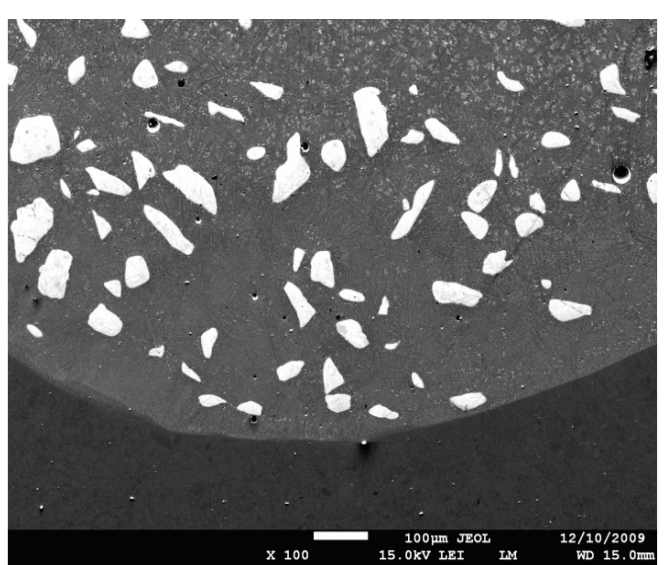

Fig. 2 - SEM photograph of cross-section of composite laser clad coating deposited by $3.7 \mathrm{~kW}$

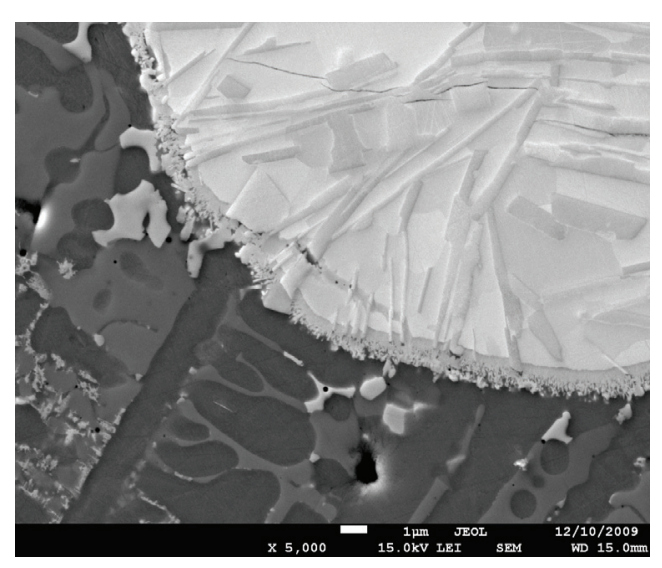

Fig. 3 - The detail of interface between $W C$ particle and $\mathrm{Ni}$ based matrix showing dissolving of WC in matrix (deposited by $3,7 \mathrm{~kW})$

Fig. 3 presents the detail of the interface of WC particle in Ni based matrix in the coating prepared by laser cladding. WC particle are partially melted and small amounts of hard phase are dispersed 
in the surrounding matrix. The microstructure of melted layers consists of a solid solution of $\mathrm{Cr}$ and $\mathrm{Fe}$ in Ni matrix forming a dendritic structure with an interdendritic lamellar eutectic phase made up mainly of $\mathrm{Ni}$, Si and $\mathrm{Cr}$-rich precipitates.

Microhardness profiles of the coatings produced by laser beams rated at 3.7 and $4.3 \mathrm{~kW}$ are compared in Fig. 4 and 5. The coatings with the highest thickness were prepared by the lowest speed of cladding $3 \mathrm{~mm} / \mathrm{s}$. The behavior of the coatings is strongly influenced by the speed of cladding. It can be seen that in both lasers the lowest hardness of $300 \mathrm{HV0.1}$ was measured by specimens prepared at a high cladding speed of $7 \mathrm{~mm} / \mathrm{s}$. hardness's of around $600 \mathrm{HV} 0.1$ are characteristic for coatings produced by the lowest cladding speed of $3 \mathrm{~mm} / \mathrm{s}$. The hardness of coatings prepared at $5 \mathrm{~mm} / \mathrm{s}$ lies between these values.

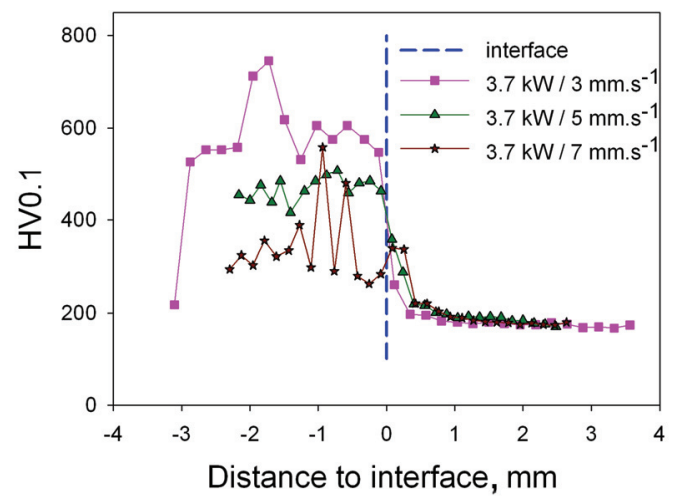

Fig. 4 - Hardness profiles of NP60+50\% WC coatings prepared by 3,7 $\mathrm{kW}$ lazer

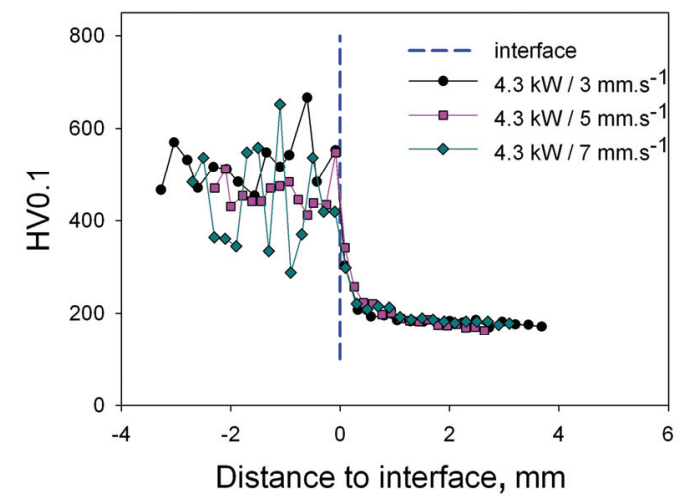

Fig. 5 - Hardness profiles of $\mathrm{NP} 60+50 \% \mathrm{WC}$ coatings prepared by $4,3 \mathrm{~kW}$ laser

In comparison with NP 60 laser coatings with a hardness of up to $700 \mathrm{HV} 0.1$ [5], the addition of 50 wt. \% of WC particles into the NP 60 matrix suggest the decrease in hardness. The decrease can be explained by the change of the chemical composition of the metals matrix due to dilution of WC particles.

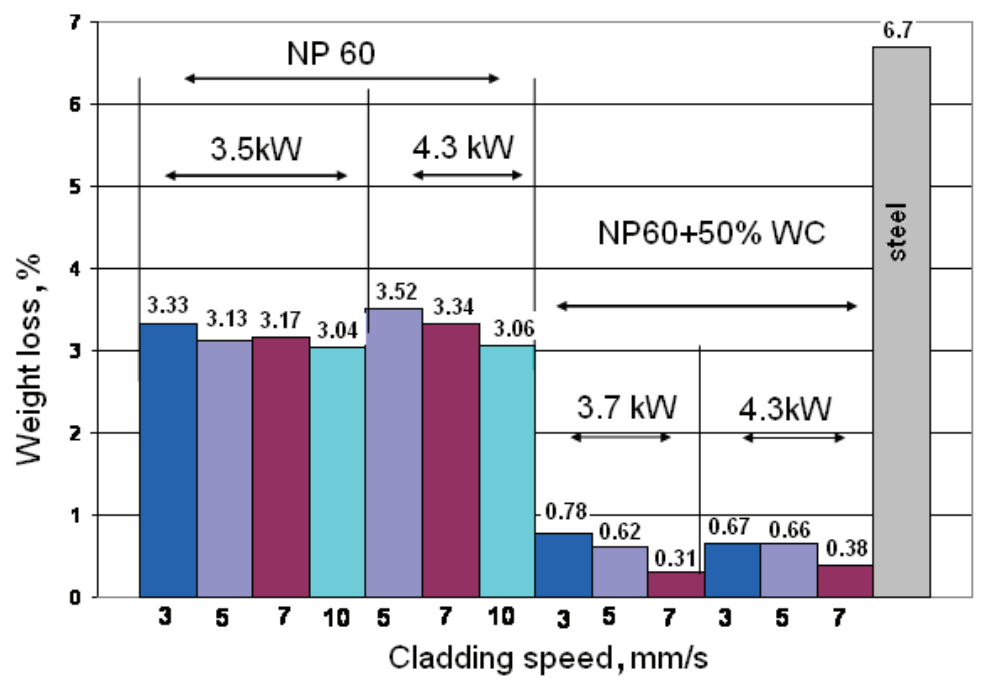


Fig. 6 - Comparison of weight losses of particular coatings after abrasion

Fig. 6 shows the comparison of weight loss after abrasion of reference steel substrate and specimens with laser clad coatings prepared by different manufacturing parameters on the $146.10^{3} \mathrm{~mm}$ track. It can be seen that the difference between steel and NiCrBSi coatings is significant. The weight loss of the substrate was about two times higher than that of NP60 coatings. These results are compared with the weight losses of investigated composite $\mathrm{NP} 60+50 \%$ WC coatings deposited by the same laser beam parameters. It can be seen that hard phase addition involves considerable increase in wear resistance properties. The weight losses of composite coatings after abrasion were dramatically lower than NP 60 coatings produced by the same parameters of laser cladding. Fig. 6 reveals that the highest weight losses are linked to composite coatings with the highest hardness of matrix produced by a low cladding speed of $3 \mathrm{~mm} / \mathrm{s}$.

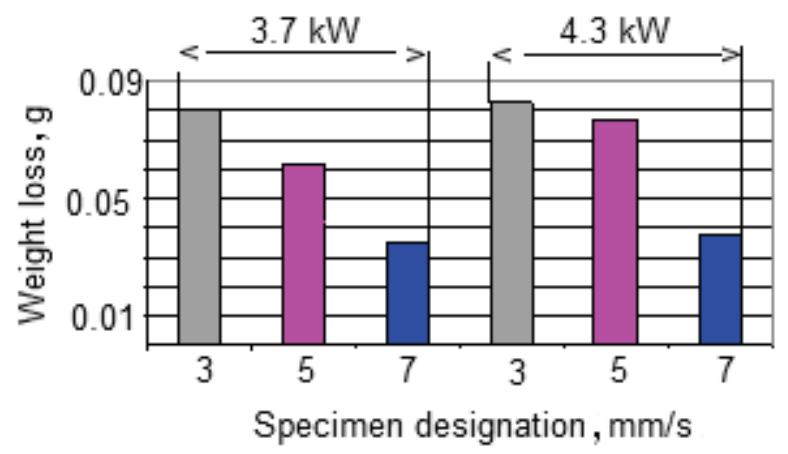

Fig. 7 - Weight losses of composite coatings after abrasion

Fig. 7 presents results of weight losses after abrasion on the $438.10^{3} \mathrm{~mm}$ track. It can be seen that the character of the graph corresponds to results of weight losses after abrasion on $146.10^{3} \mathrm{~mm}$ track, presented in Fig 6. Weight losses of particular coatings were not directly proportional to the length of abrasive track. Tripling the length of abrasion track resulted in approximately twice the weight losses. The influence of cladding speed and the particular specimen weight losses is attributed to strength of the bonding between the matrix and $\mathrm{WC}$ particle.

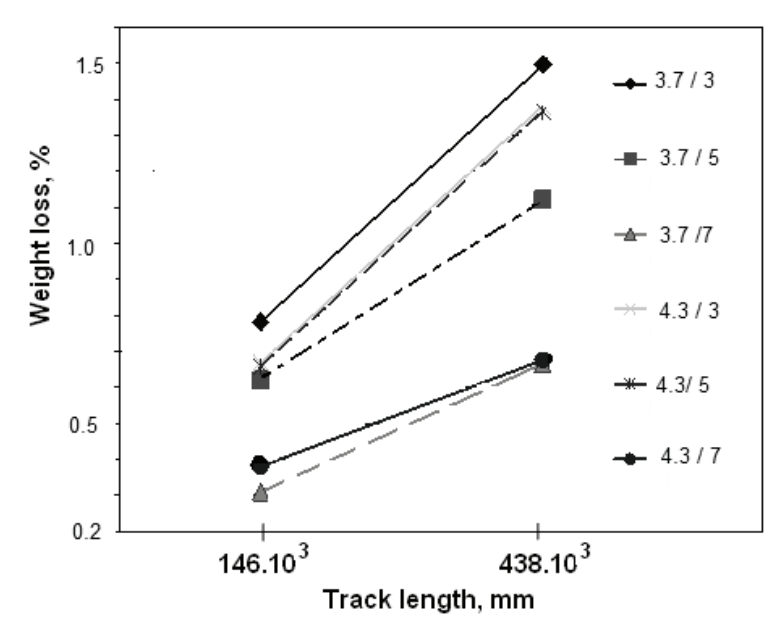

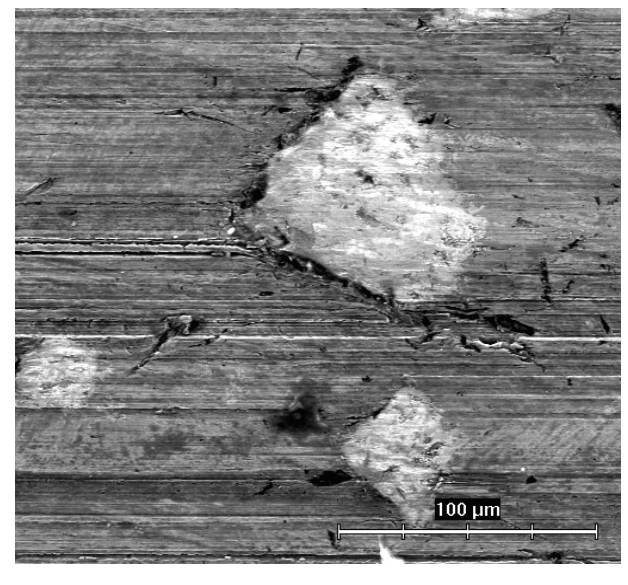


Fig. 8 - Comparison of abrasion weight losses on the track $146.10^{3}$ and $438.10^{3} \mathrm{~mm}$
Fig. 9 - SEM micrograph of the worn surface after abrasion

The influence of the track length on wear resistance for each composite coating is presented in Fig. 8. Linear increase of weight loss is characteristic for all specimens, regardless of the applied laser power. The difference can be observed only in relation to the cladding speed. Lower weight loss intensity as well as the lowest weight losses achieved by the cladding speed of $7 \mathrm{~mm} / \mathrm{s}$. Composite coatings prepared by these parameters showed the best wear resistance values. Wear surfaces were examined by electron microscopy observations to reveal mechanisms of wear behavior. The mechanism of wear abrasion was very similar for all types of coatings.

A typical worn surface is presented in Fig. 9. It reveals parallel scratches in the sliding direction caused by hard abrasive $\mathrm{SiC}$ particles in the composite coating after the test. The observations of the worn surfaces indicate grooves clearly present in the matrix. During the process of abrasive wear, surface materials are generally removed through three major mechanisms: microcutting, plastic deformation due to plowing actions, and fracture of hard-phase debris in the matrix materials. The micro-cutting is usually considered to have the most important contribution to the wear weight losses. In the present study, the WC hard phases formed a load support system that greatly reduced the load applied to the abrasives and limited the microcutting processes in the matrix, thus reducing the weight losses of composite coatings.

\section{CONCLUSIONS}

In this work, the influence of laser cladding parameters on the microstructure and abrasive wear behavior of composite $\mathrm{NiCrBSi}+50 \%$ WC coatings was analyzed. On the basis of the experimental results by two laser beam ratings and various cladding speeds, the following conclusions can be drawn:

- The value of laser beam powers 3.7 or $4.3 \mathrm{~kW}$ have no substantial effect on laser clad composite coating properties. The effect of beam scanning speed is more obvious.

- Two body abrasion of the coatings in a pin-on-disc test on abrasive paper with $\mathrm{SiC}$ grains proves the beneficial effect of WC carbides in coatings.

- The weight losses after abrasion of NP 60 specimens without WC particles are around 5 times higher than the weight losses by NP60+50\% WC specimens. Better abrasion wear properties by composite coatings were achieved in spite of a lower matrix hardness.

- Enhanced wear resistance of WC composite coatings is attributed to the hard phase structures in coatings that form a load support system which greatly reduces the load applied to the abrasives and limits microcutting processes caused by abrasion.

\section{ACKNOWLEDGEMENTS}

The support of a grant VEGA 1/0278/10 from Ministry of Education of Slovak Republic is gratefully acknowledged.

\section{REFERENCES}

[1] MigUELI, J.M., GUILEMANY, J.M., VICZIANO, S.: Tribology International 36 (2003), pp. 181186

[2] MINGXLI, L., YIZIDU, H., GUOXIONG, S.: Applied Surface Science 230 (2004), pp. 201206

[3] WANG, H., XIA, W., JIN, J: Wear 195 (1996), pp. 47--52

[4] WU, P. et al.: Wear 257(2004), pp. 142-147 
SCIENTIFIC PROCEEDINGS 2011, Faculty of Mechanical Engineering, STU in Bratislava Vol. 19, 2011, pp. 44-50, DOI: 10.2478/v10228-011-0008-x

[5] IŽDINSKÁ, Z., NASER, A., IŽDINSKÝ, K.: Materials engineering-Materiálové inžinierstvo. - Vol. 17, No. 1 (2010), p. 11-16 